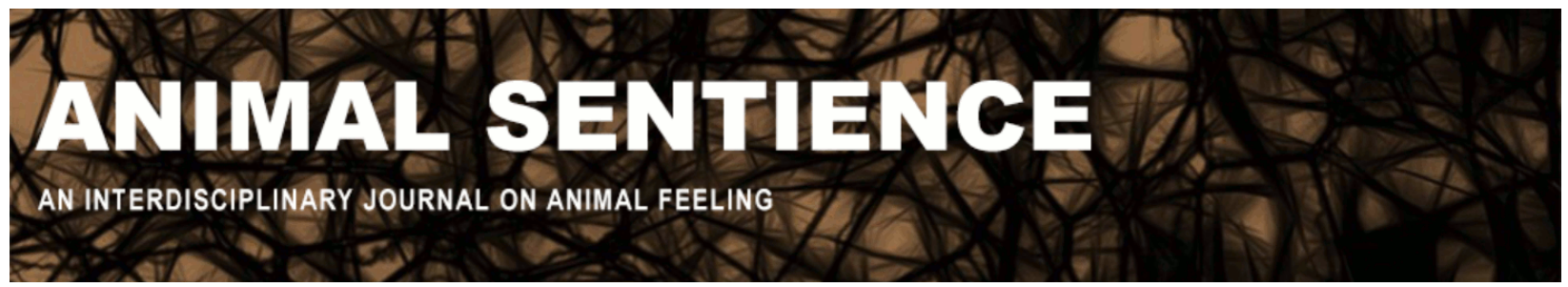

Proctor, Helen (2016) Monkey say, monkey do, monkey grieve?. Animal Sentience 4(7)

DOI: $10.51291 / 2377-7478.1025$

Date of submission: 2015-09-21

Date of acceptance: 2015-12-13

(c) (†)

This article has appeared in the journal Animal

Sentience, a peer-reviewed journal on animal

cognition and feeling. It has been made open access,

free for all, by WellBeing International and deposited

in the WBI Studies Repository. For more information,

please contact

wbisr-info@wellbeingintl.org.

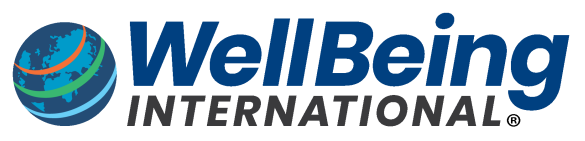

SOLUTIONS FOR PEOPLE, ANIMALS AND ENVIRONMENT 


\title{
Monkey say, monkey do, monkey grieve?
}

Commentary on King on Animal Grief

\author{
Helen Proctor \\ World Animal Protection
}

\begin{abstract}
In this commentary, I have focused on King's chapter "Do monkeys mourn?" and discussed the complexity that this question unearths. Attempting to answer this question, King has scoured the literature and talked to many primatologists to try to unravel the complex reactions seen in monkeys. From ignorance to denial, and everything in between, monkeys appear to react to death in countless ways. This commentary discusses some of the key cases for and against monkey grief, and concludes by noting the dearth of conclusive literature on one of the most studied groups of animals.
\end{abstract}

\footnotetext{
Helen Proctor helenproctor@worldanimalprotection.org is the Sentience Manager for World Animal Protection. She is an expert in the science of animal sentience and is completing her PhD with a focus on positive emotions. Recent researches potential measures of emotions in dairy cows, analysing both behavioural and physiological indicators.

www.worldanimalprotection.org
}

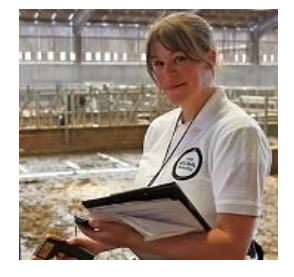

Barbara King (2013) tackles a complex subject in her book How Animals Grieve. Grief is often considered to be a higher ability, one that is unique to us humans, yet King has provided a balanced case for the capacity of animals to grieve. Due to the context and nature of grief, the stories are often anecdotal and unsuitable for rigorous testing in successive experiments. This does not necessarily mean that grief cannot be studied in a scientifically robust way. Grief is not a phenomenon that lends itself easily to such an approach, and King has done an excellent job in reviewing the extensive literature on animal grief and providing us with both engaging and factual accounts of animals experiencing grief. The many stories and accounts that King describes show us one thing; many species can grieve. They don't always appear to, and perhaps not all species can, or at least we don't know about all species just yet, but King has collated some fascinating accounts from scientists all over the world, of what can only be described as animal grief.

In Chapter 6 ("Do monkeys mourn?"), King tackles the complex array of evidence for and against monkey grief covering Toque and Japanese macaques, Baboons, and Titi monkeys. Here King discusses the many cases where monkeys are seen to show no emotional response to a familiar or related monkey's death, and then other times when they show a clear emotional response. Monkeys are wild animals, and from an evolutionary perspective some would say that it is not advantageous for them to expend the energy grieving, as this would detract from time spent foraging and reproducing. King poses this as her null hypothesis and sets about assessing a collection of studies and anecdotes of various species of monkey grief. 
Corpse carrying, for example, has been seen in many monkey species, and primatologists have various views on what it means. The mother carries her dead infant for hours or days, and some have been observed carrying them for weeks. King describes how such behaviour is counterproductive: carrying an infant restricts the mother's use of her limbs for climbing and foraging, which would be costly in terms of energy, a behaviour that is the opposite of what the null hypothesis would predict. Furthermore, those carrying them to the point where the body begins to decompose risk being alienated from the group as the group members distance themselves from the decaying corpse. Yet, scientists Cheyney and Seyfarth suggest that in baboons at least, they are actually expressing a sense of ownership over the infant. They argue that this is what drives the mother, and often group members, to guard the deceased infant from other baboons and humans. Corpse carrying is a complex phenomenon, and this is just one theory; scientists don't yet know for sure what drives one mother to carry her infant for weeks on end, whereas others drop them immediately and appear to carry on with their lives unaffected.

In her extensive literature review, King came across one attempt at measuring the physiological elements of grief. She discusses how Engh et al. found that glucocorticoid, a stress hormone found in faeces, was significantly higher in baboons who had witnessed predation on a close relative, compared with those who witnessed predation on an unrelated baboon. But as this evidence is unsupported by any robust behavioural accounts of baboon grief, King refrains from drawing any conclusions as to its meaning.

It is clear from this fascinating chapter that there is still much work to be done in this field before robust conclusions can be drawn about the capacity of monkeys to grieve. Unlike elsewhere in her book, King reserves drawing any conclusions regarding her view on monkey grief. There are many different monkey species, and they are adapted to all sorts of environments and social structures. Perhaps King was too ambitious in attempting to determine whether all monkey species can grieve; she might have been more successful if she had focussed on smaller sub-groups of monkeys who have similar pressures and social groups. One thing is certain: there is still much more to learn about monkeys. Monkeys represent one of the most studied animal groups of the kingdom, yet it is surprising how little we really know about them and their emotional minds. The latter can be said of all species of the animal kingdom, as we scientists are only recently beginning to make some progress in measuring and understanding the complex emotional lives of non-human animals.

\section{References}

King, B. J. (2013) How animals grieve. University of Chicago Press 